\title{
Leaking in silence: women with stress urinary incontinence who do not have access to or refuse surgery
}

\author{
Renly Lim ${ }^{1,2}$ (D) Men Long Liong ${ }^{3} \cdot$ Kah Hay Yuen ${ }^{1}$ \\ Received: 14 October 2017 / Accepted: 20 December 2017 / Published online: 8 January 2018 \\ (C) The International Urogynecological Association 2018
}

Research on stress urinary incontinence (SUI) is usually conducted in high-income countries, with more emphasis on surgical interventions [1]. The current mainstay for surgical treatment of SUI is the minimally invasive procedure using a vaginal mesh sling. In recent years, following reports of mesh complications, international authorities have issued alerts regarding the use of mesh, while the controversy has garnered significant media attention [2-4]. Accruing evidence shows that mesh is safe in the case of SUI $[1,5]$. However, what is missing from the bigger picture is that these results mean very little to low- and middle-income countries, where surgical interventions for SUI are either not commonly available or may not be performed due to sociocultural barriers.

There continues to be a research gap between developed and developing countries. Given the lack of access to or poor acceptance of incontinence surgery in such regions, it seems plausible to presume that pelvic floor muscle training (PFMT), which is recommended as the first-line nonsurgical treatment, will be used. However, many women have limited understanding of PFMT or do not know how to contract the correct muscles. For many low- and middle-income countries, including Malaysia, there are very few, if any, continence physiotherapy centers that offer PFMT. Most women have never received instructions from their healthcare providers. Furthermore, compliance with PFMT is questionable. The most significant barrier to compliance is that patients perceive it has minimal benefits [6]. Other nonsurgical interventions that may be available

Renly Lim

renly_lim@hotmail.com

1 School of Pharmaceutical Sciences, Universiti Sains Malaysia, 11700 Penang, Malaysia

2 Quality Use of Medicines and Pharmacy Research Centre, School of Pharmacy and Medical Sciences, University of South Australia, Adelaide, Australia

3 Department of Urology, Island Hospital, Penang, Malaysia include biofeedback, mechanical devices (e.g., vaginal pessaries), electrical or magnetic stimulation, and complementary therapies (e.g., acupuncture). Some treatment options, such as pessaries and electrical stimulation, may be less popular than others because they involve insertion of a foreign object into the vagina. However, despite the shortcomings of nonsurgical treatments, many patients find these methods more acceptable to manage SUI than invasive surgery.

It is true that nonsurgical methods are not as effective as surgical methods, yet it is also true that many patients in such regions do not have access to or do not want to undergo surgical treatment. We believe that more effort should be channelled into promoting conservative treatments and educating the public about the myriad nonsurgical options available. More studies could be done to investigate new nonsurgical treatment options or refine existing options. Clinicians have the onus of discussing all possible treatment options with their patients, taking into account availability, efficacy, and acceptability; risk of adverse events; and patients' motivation. As healthcare professionals, we should scale up efforts to raise awareness about SUI diagnosis and management. For example, lifestyle and behavioral advice (e.g., appropriate fluid intake, weight management, and smoking cessation) are simple methods that can significantly improve quality of life of not only women with incontinence but also for members of the general public.

In conclusion, we urge that more focus be given to women Iwhere there is little access to or who are unwilling to undergo minimally invasive treatment. With the hype about efficacy of (or potential lawsuits following) surgery for SUI in developed countries, it is a grave disservice that millions of women with SUI in underserved regions continue to suffer from the condition no one wants to talk about. With $80 \%$ of all older people projected to live in low- and middle-income countries by 2050 [7], women with SUI are likely to suffer longer. Researchers, policy makers, and healthcare professionals should work together to improve education and public awareness related to SUI so that these women do not continue to "leak in silence." 


\section{Compliance with ethical standards}

\section{Conflict of interest None.}

\section{References}

1. Morling JR, McAllister DA, Agur W, Fischbacher CM, Glazener CMA, Guerrero K, et al. Adverse events after first, single, mesh and non-mesh surgical procedures for stress urinary incontinence and pelvic organ prolapse in Scotland, 1997-2016: a populationbased cohort study. Lancet. 2017;389(10069):629-40. https://doi. org/10.1016/S0140-6736(16)32572-7.

2. Australian Government Department of Health Therapeutic Goods Administration. Urogynaecological surgical mesh complications. 2016 https://www.tga.gov.au/alert/urogynaecological-surgicalmesh-complications. Accessed 16 Sept 2017.

3. U.S. Food and Drug Administration. Urogynecologic surgical mesh implants. $2017 \mathrm{https} / / \mathrm{www} . f d a . g o v / M e d i c a l D e v i c e s /$
ProductsandMedicalProcedures/ImplantsandProsthetics/ UroGynSurgicalMesh/default.htm. Accessed 28 Sept 2017.

4. The Conversation. Vaginal mesh controversy shows collective failure of the TGA and Australia's specialists. 2017 https:// theconversation.com/vaginal-mesh-controversy-shows-collectivefailure-of-the-tga-and-australias-specialists-78605. Accessed 28 Sept 2017.

5. Ford AA, Rogerson L, Cody JD, Aluko P, Ogah JA. Mid-urethral sling operations for stress urinary incontinence in women. Cochrane Database Syst Rev. 2017;7:CD006375. https://doi.org/10.1002/ 14651858.CD006375.pub4.

6. Frawley HC, McClurg D, Mahfooza A, Hay-Smith J, Dumoulin C. Health professionals' and patients' perspectives on pelvic floor muscle training adherence-2011 ICS state-of-the-science seminar research paper IV of IV. Neurourol Urodyn. 2015;34(7):632-9. https://doi.org/10.1002/nau.22774.

7. World Health Organisation. Ageing and health. 2015 http://www. who.int/mediacentre/factsheets/fs404/en/. Accessed 25 Sept 2017. 